\title{
Evaluating toxicity of extracted nano -Destruxin against the desert locust Schistocerca gregaria in Egypt
}

\author{
Magda M. Sabbour \\ Pests and Plant Protection Dep., National Research Centre ,Dokki, Cairo Egypt. El- Behouth St., \\ P.O. Box 12622, Dokki, Cairo, Egypt \\ E-mail: sabbourm9@yahoo.com
}

\begin{abstract}
Nano destruxin tested under laboratory and semifield condition. Results show that the $\mathrm{LC}_{50}$ S of the locust $S$. gregaria after treatment with destruxin, $210 \times 10^{4}, 221 \times 10^{4}, 250 \times 10^{4}$ spores/ml, of newly hatched nymphs last nymphal stage and adult stage., respectively. The results show that, the $\mathrm{LC}_{50} \mathrm{~S}$ of the corresponding stages significantly decreased after treated with the nano-destruxin which is recode, $99 \times 10^{4}, 106 \times 10^{4}$ and $114 \times 10^{4}$ spores $/ \mathrm{ml}$. Under semi field condition, the $\mathrm{LC}_{50}$ s of newly hatched nymphs, last nymphal stage and adult stages, $210 \times 10^{4}, 227 \times 10^{4}$ and $224 \times 10^{4}$ spores $/ \mathrm{ml}$.

The effect of nano-destruxin against $S$. gregaria under semi-field conditions show that after 20 days, the infestations number were significantly decreased to $2.2 \pm 1.2$, as compared to $2.4 \pm 5.3$, and 12.2 \pm 2.2 individuals after treated with destruxin and in the control. After 90 days of the post applications, the corresponding infestations, recorded that, 20 $\pm 8.9,18 \pm 3.4$ and $60 \pm 4.9$ individuals, respectively. After 120 days the infestations number significantly decreased to $29 \pm 8$.9individuals after treated with nano-destruxin.
\end{abstract}

Key words: Destruxin, Metarhizium anisopliae, Schistocerca gregaria, microbial agent.

\section{INTRODUCTION}

Nanotechnology is a promising field of interdisciplinary research. It opens up a wide array of opportunities in various fields like medicine, pharmaceuticals, electronics and agriculture. The potential uses and benefits of nanotechnology are enormous. These include insect pests management through the formulations of nanomaterials-based pesticides and insecticides, enhancement of agricultural productivity using bio-conjugated nanoparticles (encapsulation) for slow release of nutrients and water, nanoparticle-mediated. Desert locust Schistocerca gregaria bioassayed by using the nano destruxin leaves containing early stages larvae. Sabbour (2013) showed that range of mortality was between $64-85 \%$ based on the end point data. Bioassay of destruxin by against desert locust Schistocerca gregaria nymphs showed its acceptable effect of destruxin. By considering biology of this species and calculated $\mathrm{LC}_{50} \mathrm{~s}$, destruxin seems to be effectiveness.

The life history of the desert locust, Schistocerca gregaria (Forsk.), and the epidemiology of its outbreaks were obscure until the 20th Century. One of the discoveries of importance in this century was that of solitary and gregarious phases. A most prominent feature of the 'arbeh' is that it can exist as scattered individuals within the 'recession areas' or, when gregarious, as swarms throughout the 'invasion areas'. This is because the locust exists in different phases. When breeding conditions lead to an increase in the number of locusts crowded together, the 


\section{Magda M. Sabbour}

insects have the ability to change their color, behavior, shape and physiology, with color and behavior being the characteristics to change first.

All grasshoppers (except for the so-called long-horned grasshoppers) belong to the superfamily Acridoidea; the most important locusts are all in the family Acrididae. The extensive devastation caused by insect pests to crops and pasture lands since antiquity have left a profound impact on historical records from all over the ancient Middle East. One of the best known examples is the vivid description of a desert locust invasion by the prophet Joel in the Bible, referring to the ravages of the huge swarms of hoppers. Of the ten plagues which, according to the Old Testament, the Lord inflicted on Pharaoh's Egypt, three were insect plagues, namely, lice, flies and locusts.

Egypt, from 4500 years ago (Amer et al., 2008; Uvarov, 1977 and 1966). More than 300 species of locusts and grasshoppers are known to exist in the African continent FAO (1995), but fortunately only a few of them are major pests; most are sedentary, inhabiting a rather confined area throughout their life cycle. Only few species are highly mobile, migrating from one location to another with ecological conditions more suitable for feeding and reproduction. The desert locust in Africa exhibits fully gregarious characteristics and is known for its long-range pattern of migration, covering as many as several thousand kilometers within a single generation. This is the main reason why the locust was, not surprisingly, the most feared among agricultural pests in antiquity. Although our knowledge regarding plant protection problems in antiquity in the Near East is generally limited, some sources, such as the Biblical and Rabbinical (Halakha and Midrash) literature, go into more detail when referring to the desert locust. Greek and Roman literature also deal extensively with various aspects of 'a kris' and 'locusta', (for the terms of these locusts and other pests belonging to the order Orthoptera), respectively. Under such conditions not only the flora and fauna are multifarious, but also their pathogens, predators and parasites, which include all sorts of animals - invertebrates as well as vertebrates, and lower and higher plants. It may be assumed that proliferation of the pathogens and parasites was often counterbalanced in ancient times by natural enemies. It is not clear whether this applies also to locusts.

The aim of this work is to evaluate the toxicity of extracted nano-destruxin from the fungus Metarhizium anisopliae against the desert locust Schistocerca gregaria in Egypt.

\section{Insect rearing}

\section{MATERIALS AND METHODS}

Locust was reared under laboratory condition for several generations on semi-artificial diet as mentioned by Sharaby et al. (2010).

\section{Entomopathogenic Fungus:}

The fungus, Metarhizium anisopliae isolated were obtained in a series of soil screening experiments by using 200 samples (Ghanbary et al., 2009). The isolates were inoculated in 50 $\mathrm{mL}$ Potato Dextrose Broth (PDB) mediums for destruxin production. The medium was filtered using filter paper seven days after culturing. Then $10 \mathrm{~mL}$ chloroform was added and shake vigorously for $10 \mathrm{~min}$. The supernatant evaporate and the residue was containing destruxin. The residues were dissolved in $10 \mathrm{~mL}$ distilled water and stored at $-20^{\circ} \mathrm{C}$ for further examinations. Bioassays: The fresh citrus leaves containing CLM larvae were collected daily and the ones including at least 10 early stages larvae used in experiments. The rate of 10 larvae per leaf was 


\section{Evaluating toxicity of extracted nano -Destruxin against the desert locust Schistocerca gregaria in Egypt}

provided by killing the additional larvae before treatment. The extracted destruxin and 10, 15 and 20 -fold dilutions were used in bioassays. The prepared leaves were dipped in concentrations for $10 \mathrm{sec}$ and allowed to dry for about one hour. The treated leaves were placed in Petri dishes and held in incubator conditions $\left(27 \pm 1^{\circ} \mathrm{C}\right)$. The bioassays were replicated four times for any isolate and dilution and the control was containing only distilled water. Mortality was recorded at 1, 2, 3 and 4 days after treatment. The larvae with no movement were recorded as died ones. The probit and T-test options of SPSS software were used for analyzing time-mortality and comprising means of mortality, respectively. The percentages of mortality were calculated after seven days and corrected according to Abbott, (1925), while LC $_{50}$ was calculated through probit analysis of Finney (1964).

\section{Preparation of the nano-destruxin.}

The extracted destruxin were prepared to nano-particles by national research center microbiological team according to Leiderer et al. (2008). Then prepared for scanning microscopy.

\section{RESULTS AND DISCUSSION}

Data in Table (1) show that the $\mathrm{LC}_{50} \mathrm{~S}$ of the locust $S$. gregaria after treated with destruxin were $210 \times 10^{4}, 221 \times 10^{4}, 250 \times 10^{4}$ spores $/ \mathrm{ml}$. of newly hatched nymphs last nymphal stage and adult stage, respectively. Table (2) shows the $\mathrm{LC}_{50} \mathrm{~S}$ of the corresponding stage significantly decreased after treated with the nano-destruxin which is recode, $99 \times 10^{4}, 106$ X $10^{4}$ and $114 \times 10^{4}$ spores $/ \mathrm{ml}$.

Under semi field condition, the $\mathrm{LC}_{50} \mathrm{~s}$ of newly hatched nymphs, last nymphal stage and adult stages were $210 \times 10^{4}, 227 \times 10^{4}$ and $224 \times 10^{4}$ spores $/ \mathrm{ml}$, respectively (Table 3 ).

The effect of nano-destruxin against $S$. gregaria under semi-field conditions show that after 20 days, the infestations number was significantly decreased to $2.2 \pm 1.2$. As compared to $2.4 \pm 5.3$, and 12.2 \pm 2.2 individuals after treatment with destruxin and in the control, respectively (Table 4). After 90 days of the post applications, the corresponding infestations, recorded were $20 \pm 8.9,18 \pm 3.4$ and $60 \pm 4.9$ individuals , respectively. After 120 days the infestations number significantly decreased to $29 \pm 8.9$ individuals after treated with nano-destruxin (Table 4).

Figure (1) shows the nano destruxin particles with scanning electron microscopy. Figure (2) shows that the laboratory experiments indicated that the nano-destruxin is the most effective against the locust $S$. gregaria comparing with the destruxin and the control. Figure (3) shows that the infestations of the locust $S$. gregaria under semi field conditions comparing the destruxin and non -destruxin which show that the infestation percent significantly decreased after treated with nano -destruxin.

The entomopathogenic fungus Metarhizium anisopliae is a well studied and applied species for microbial control of insect pests (Liu et al., 2007; Hoe et al., 2009). This fungus produces some cyclic peptides, destruxins (Hsiao and Ko, 2001) which may play a role in its pathogenicity (Kershaw et al., 1999). More than 35 different structurally related destruxins have been isolated from cultures of $M$. anisopliae (Pedras et al., 2002). Destruxin capacity in control practices is a less studied matter, but some investigations have described its insecticidal properties (Brousseau et al., 1996; Thomsen and Eilenberg, 2000). Sabbour (2013a and b) examined the effect of different dilutions of destruxins extracted from several fungal isolates on desert locust. 


\section{Magda M. Sabbour}

Although the mode of action of destruxins in insects is an unclear issue but altering the calcium cannels function has proposed in some investigations (Dumas et al., 1996; Samuels et al., 1988). Primarily, tetanic paralysis is the common symptom in insects causing by application of destruxin (Samuels et al., 1988). Opening the $\mathrm{Ca}^{2+}$ channels as a result of membrane depolarization by destruxin has been implicated as a cause of paralysis and death (James et al., 1993). Humoral immune response seems to be specifically affected by destruxin (Pal et al., 2007). Taken together these findings describe the probable reason for slow-acting this mycotoxin. Recording mortality data after the minimum of $72 \mathrm{~h}$ is a common procedure. Based on the present data, three to four days after treatment appear to be appropriate final point for recording mortality. Expensive production of microbial biopesticides is one of the limiting factors for wide application of these agents (Lacey, 2008; Dezianian et al., 2010). Thus for investigating a cost effective procedure CLM larvae were examined by serial dilutions (10, 15 and 20 folds) of destruxins (Mohammadi Sharif, et al., 2010). In many cases, entomopathogens are potential control agents against pests and use along with other component of integrated pest management (Kaya and Lacey, 2007). Therefore, the dilutions of extracted destruxin are suitable candidates in these programs; they decrease application's cost of destruxin in an integrated procedure. (Mohammadi Sharif, et al 2010) reported that, 10-fold dilution of A-115 seems to be a good example of an accompanying agent in these programs. Like other microbial agents, long period of lethal infection (Lacey, 2008) is a disadvantage of destruxins. This make the LT $_{50}$ value consider as a significance parameter. The first three instars are active and feed within the mines, while the forth instar, no longer feed and produces silk from its mouthparts to form a pupal chamber. Growth of three stages takes about five to six days in summer (Beattie and Hardy, 2004), but in different environmental conditions it may be longs one to three weeks (BaAngood, 1978; Godfrey and Grafton-Cardwell, 2002; Grafton-Cardwell, 2009). By considering the biology of CLM and the LT $_{50}$ s of isolates (Mohammadi Sharif et al., 2010), destruxin have acceptable efficacy on CLM. Also, these measures suggest that three to four days after treatment is a suitable endpoint for destruxin bioassay. On the other hand, fungus contamination of the food source could repel larvae and thus reduce their food consumption, as was shown for the grasshopper Stiphra robusta exposed to leaves sprayed with $M$. anisopliae var. acridum (Magalhaes et al., 2001). Also, Mohammadi Sharif et al. (2010) reported that, Microbial agents are a suitable and naturally friend part of integrated pest management programs. Extracted destruxin from the fungi, $M$. anisopliae can be used as a constituent of citrus leafminer control measures. Like many of microbial agents, the slow acting property of destruxin should be considered in citrus leafminer measures. However, before it is used as a component of an IPM procedure, its compatibility with other biocontrol agents such as beneficial insects and the pesticides used in citrus orchards has to be examined.

Table 1. Effect of destruxin against the desert locust $S$. gregaria under laboratory conditions.

\begin{tabular}{|l|lccc|}
\hline Stages & LC & V & S & 95\% confidence limits \\
\hline Newly hatched nymphs & $210 \times 10^{4}$ & 0.01 & 1.3 & $201-227$ \\
Last nymphal stage & $221 \times 10^{4}$ & 0.01 & 0.2 & $211-277$ \\
Adult & $250 \times 10^{4}$ & 0.01 & 1.2 & $222-289$ \\
\hline
\end{tabular}


Evaluating toxicity of extracted nano -Destruxin against the desert locust Schistocerca gregaria in Egypt

Table 2. Effect of nano-destruxin against the desert locust $S$. gregaria under laboratory conditions.

\begin{tabular}{|l|lccc|}
\hline Stages & LC & V & S & 95\% confidence limits \\
\hline Newly hatched nymphs & $99 \times 10^{4}$ & 0.01 & 1.3 & $88-227$ \\
Last nymphal stage & $106 \times 10^{4}$ & 0.02 & 0.2 & $97-277$ \\
Adult & $114 \times 10^{4}$ & 0.03 & 1.2 & $99-289$ \\
\hline
\end{tabular}

Table 3. Effect of nano-destruxin against the desert locust $S$. gregaria under semi-field conditions.

\begin{tabular}{|l|lccc|}
\hline Stages & LC & V & S & 95\% confidence limits \\
& & & & \\
\hline Newly hatched nymphs & $210 \times 10^{4}$ & 0.01 & 1.3 & $200-247$ \\
Last nymphal stage & $227 \times 10^{4}$ & 0.01 & 0.1 & $210-279$ \\
Adult & $244 \times 10^{4}$ & 0.01 & 1.1 & $202-299$ \\
\hline
\end{tabular}

Table (4): Effect of nano-destruxin against $S$. gregaria under semi-field conditions.

\begin{tabular}{|l|l|l|}
\hline Treatments & Days after treatment & infestations of the target pests \\
\hline Control & 20 & $12.2 \pm 2.2$ \\
& 50 & $29 \pm 3.9$ \\
& 90 & $60 \pm 4.9$ \\
& 120 & $88 \pm 6.9$ \\
\hline Destruxin & 20 & $2.4 \pm 5.3$ \\
& 50 & $10 \pm 4.4$ \\
& 90 & $18 \pm 3.4$ \\
Nano- destruxin & 120 & $24 \pm 2.9$ \\
& 20 & $2.2 \pm 1.2$ \\
& 50 & $19 \pm 3.9$ \\
& 90 & $20 \pm 8.9$ \\
& 120 & $29 \pm 8.9$ \\
\hline
\end{tabular}


Magda M. Sabbour

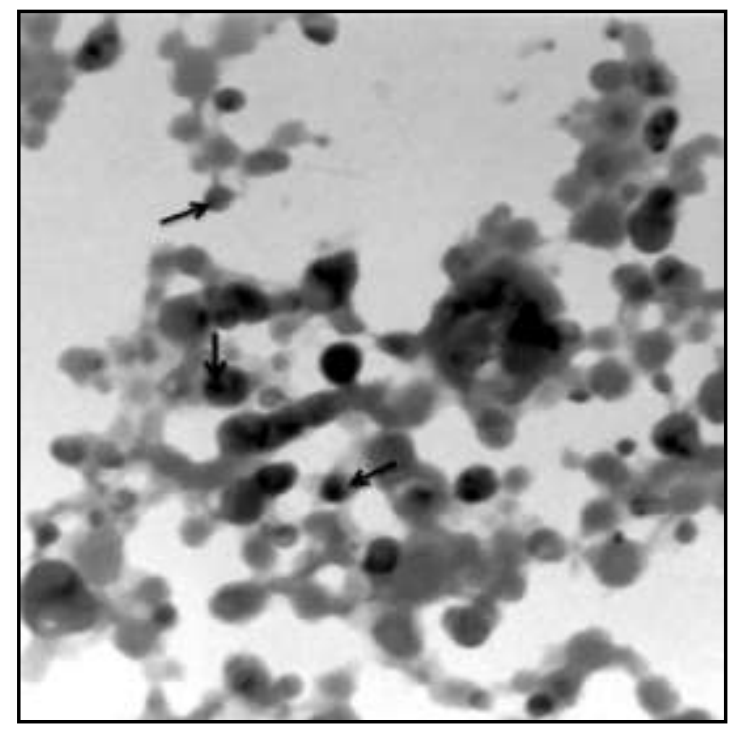

Fig.1. Nano destruxin scanning electron microscopy.

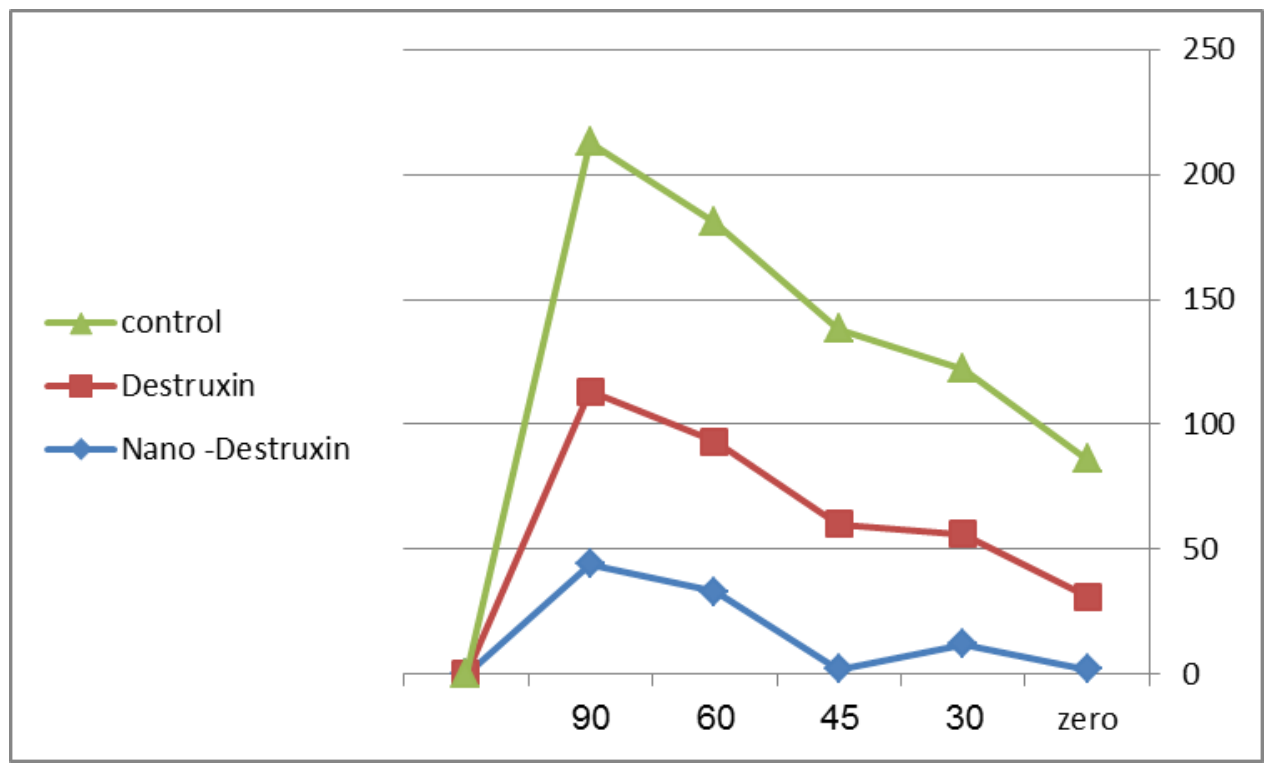

Fig . 2: Percentage of infestations of the locust $S$. gregaria under laboratory conditions after treatments 


\section{Evaluating toxicity of extracted nano -Destruxin against the desert locust Schistocerca gregaria in Egypt}

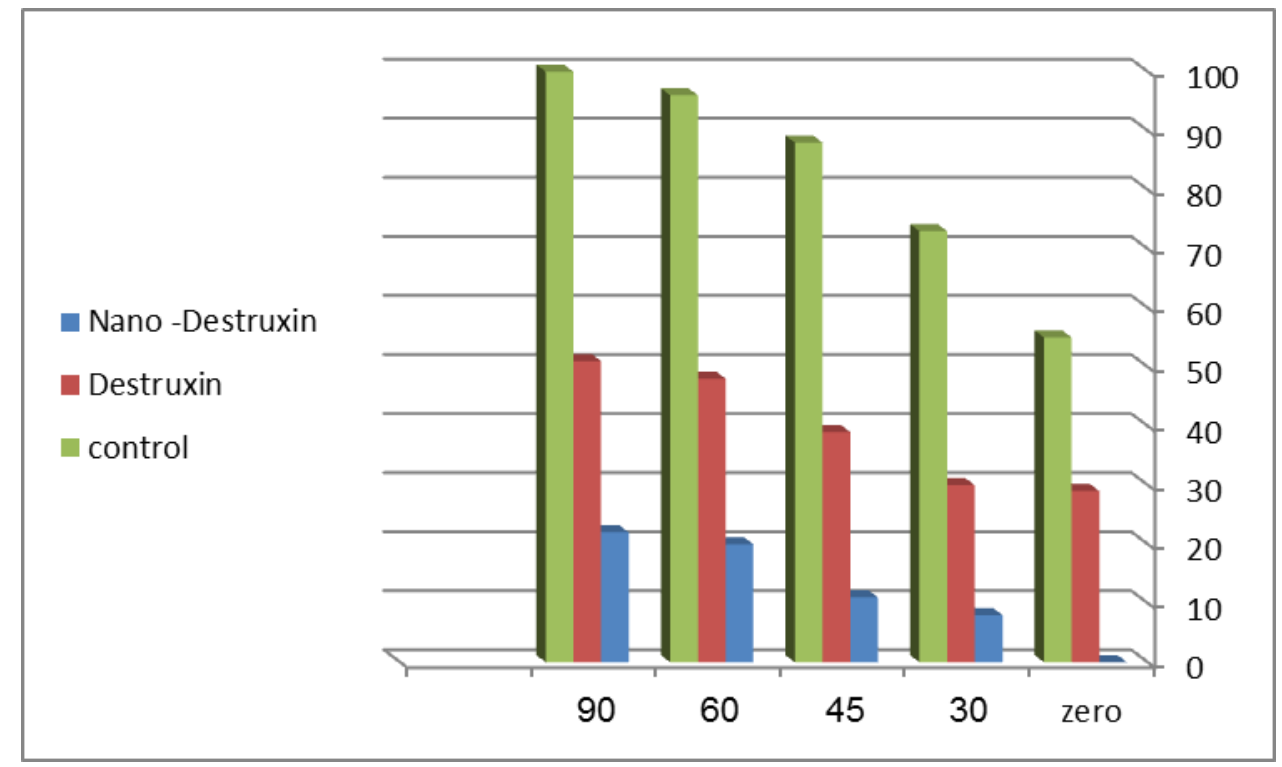

Fig. 3: Percentage of locust infestations percentage of infestations of the locust $S$. gregaria under semi field conditions after treatments.

\section{REFERENCES}

Abbott, W. S. (1925). A method of computing the effectiveness of an insecticide. J. Econ. Ent., 18: $265-267$.

Amer, M.M.; T.I. El-Sayed; H.K. Bakheit; S.A. Moustafa and Yasmin A. El-Sayed (2008). Pathogenicity and Genetic Variability of Five entomopathogenic fungi against Spodoptera littoralis. Res. J. Agric. and Biolog. Sci., 4(5): 354-367 .

Beattie, A. and S. Hardy (2004). Citrus leafminer. NSW Department of Primary Industries. http://www.dpi.nsw.gov.au/data/assets/pdf_file/0006/137634/citrus- leafminer.pdf

Brousseau, C.; G. Charpentier and S. Belloncik (1996). Susceptibility of spruce budworm, Choristoneura funiferana Clemens, to destruxines, cyclopeptidic mycotoxins of Metarhizium anisopliae. J. Invertebr. Pathol., 68: 180-182. DOI: 0.1006/jipa.1996.0079.

Dezianian, A.; A.S. Sajap; W.H. Lau; D. Omar and H.A. Kadir et al. (2010). Morphological characteristics of P. xylostella granulovirus and effects on its larval host diamondback moth Plutella xylostella L. (Lepidoptera, Plutellidae). Am. J. Agric. Biol. Sci., 5: 4349. http://www.scipub.org/fulltext/AJAB/AJAB5143- 49.pdf

FAO (1995). Desert Locust Control Committee. Report of the Thirty-Third Session. FAO, Rome, Italy.

Finney, D. J. (1964). Probit analysis. $2^{\text {nd }}$ Ed., Cambridge. Univ. Press. England. 318 PP.

Ghanbary, M.A.T.; A. Asgharzadeh; A.R. Hadizadeh and M.M. Sharif (2009). A quick method for Metarhizium anisopliae isolation from cultural soils. Am. J. Agric. Biol. Sci., 4: 152-155. http://www.scipub.org/fulltext/AJAB/AJAB42152- 155.pdf. 


\section{Magda M. Sabbour}

Godfrey, K. and B. Grafton-Cardwell (2002). Citrus leafminer in California citrus. Biological Control Program.

http://www.cdfa.ca.gov/phpps/ipc/biocontrol/pdf/insects/cleafminer_citrus-may6-

02.pdf

Grafton-Cardwell, E. (2009). Citrus leafminer. University of California IPM Online. ttp://www.ipm.ucdavis.edu/PMG/r107303211.html

Kershaw, M.J.; E.R. Moorhouse; R. Bateman; S.E. Reynolds and A.K. Charnley (1999). The role of destruxins in the pathogenicity of Metarhizium anisopliae for three species of insect. J. Invertebr. Pathol., 74: 213-223. DOI: 10.1006/jipa.

Hoe, P.K; C.F.J. Bong; K. Jugah and A. Rajan (2009). Evaluation of Metarhizium anisopliae var. anisopliae (Deuteromycotina: Hyphomycete) isolates and their effects on subterranean termite Coptotermes curvignathus (Isoptera: Rhinotermitidae). Am. J. Agric. Biol. Sci., 4: 289-297. http://www.scipub.org/fulltext/AJAB/AJAB44289297.pdf.

Hsiao, Y.M. and J.L. Ko (2001). Determination of destruxins, cyclic peptide toxins produced by different strains of Metarhizium anisopliae and their mutants induced by ethyl methane sulfonate and ultraviolet using HPLC method. Toxicon, 39: 837-841. PMID: 11137544.

Lacey, L.A., (2008). Microbial Control of Insects. In: Encyclopedia of Entomology, Capinera, J.L. (Ed.). Springer, New York, ISBN: 978- 1402062421, pp: 2367-2373.

Leiderer, P. and Dekorsy, T.. (2008). Interactions of nanoparticles and surfaces Tag der mÄundlichenPrÄufung: 25. April.

http://www.ub.unikonstanz.de/kops/ volltexte/2008/5387/; http://nbn-resolving.de/urn:nbn:de:bsz:352-opus-53877

Liu, B.L.; T.M. Rou; Y.K. Rao and Y.M. Tzeng (2007). Effect of pH and aeration rate on the production of Destruxins A and B from Metarhizium anisopliae. Int. J. Applied Sci. Eng., 5: 17-26. http://www.cyut.edu.tw/ ijase/2007/012-003-3.pdf.

Magalhaes, B.P.; De Faria, M.R.; Lecoq, M.; Schmidt, F.G.V.; Silva, J.B.T.; Frazao, H.S. et al. (2001) The use of Metarhizium anisopliae var. acridum against the grasshopper Rhammatocerus schistocercoides in Brazil .J. Orthoptera Res., 10:199-202.

Mohammadi Sharif, M.; A.R. Hadizadeh and M.A. Tajick Ghanbary (2010). Evaluating Toxicity of Extracted Destruxin from Metarhizium anisopliae against citrus leafminer, Phyllocnistis citrella. Am. J. Environ. Sci., 6 (4): 379-382, 2010.

Pedras, M.S.C.; L.I. Zaharia and D.E. Ward (2002). The destruxins: Synthesis, biosynthesis, biotransformation and biological activity Phytochem., 59: 579-596.

DOI: /10.1016S0031-9422(02)00016-X.

Sabbour, M.M. (2013a). Evaluating toxicity of extracted destruxin from Metarhizium anisopliae against the desert locust Schistocerca gregaria in Egypt. J.Egypt. Acad. Environ. Develop., 14(1): 35-41.

Sabbour, M.M. (2013b). Evaluating toxicity of extracted destruxin from Metarhizium anisopliae against the grasshopper Hetiracris littoralis in Egypt. J. Egypt. Acad. Environ. Develop., 14(1): 29-34.

Thomas, M.B.; Blanford, S. and Lomer, C.J. (1997). Reduction of feeding by the variegated grasshopper, Zonocerus variegatus, following infection by the fungal pathogen Metarhizium avoviride. Biocontrol Sci. Technol., 3:327-334. 


\title{
Evaluating toxicity of extracted nano -Destruxin against the desert locust Schistocerca gregaria in Egypt
}

Thomsen, L. and J. Eilenberg (2000). Time concentration mortality of Pieris brassicae (Lepidoptera: Pieridae) and Agrotis segetum (Lepidoptera: Noctuidae) larvae from different destruxins. Environ. Entomol., 29: 1041-1047. DOI: 10.1603/0046-225X29.5.1041.

Uvarov, B.P. (1966). Grasshoppers and Locusts. A Handbook of General Acridology. Vol. 1. Cambridge University Press, Cambridge, UK.

Uvarov, B.P. (1977). Grasshoppers and Locusts. A Handbook of General Acridology. Vol. 2. Centre for Overseas Pest Research, London, UK.

\author{
تقييم سمية النانو ديستروكسين المستخرج من المياتريزيوم انيزوبيلا ضد الجراد الصحراوى \\ Schistocerca gregaria

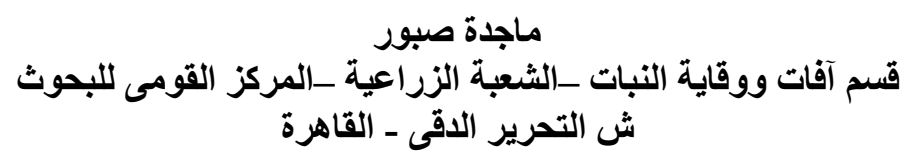 \\ E-mail: sabbourm9@yahoo.com
}

\begin{abstract}
المستخلص
الفطر ميتاريزيوم انيزوبيلا (Metschnikoff) سوركين ينتج بعض السموم واليبتيدات الفطرية الديستروكسين التى التى التئي

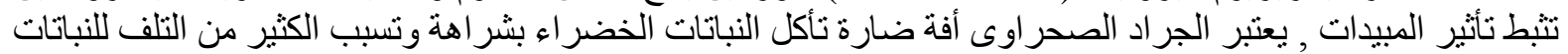

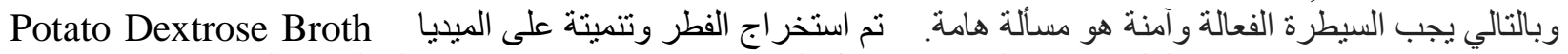

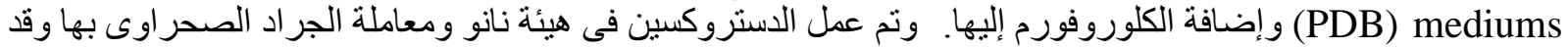

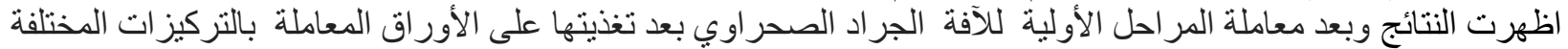

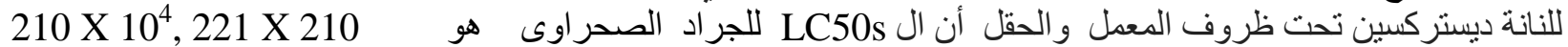
10², 250 X 104

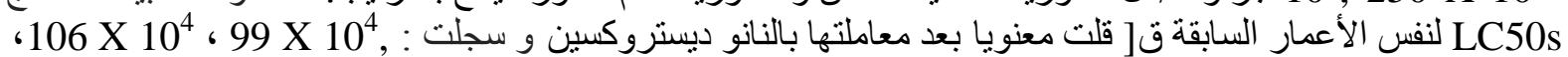

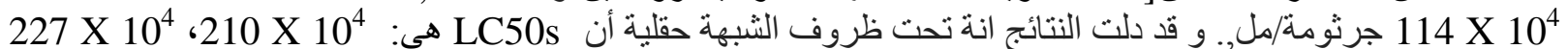

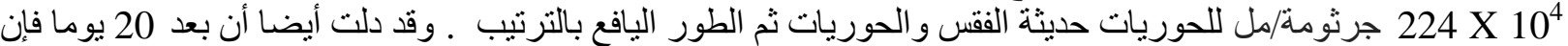

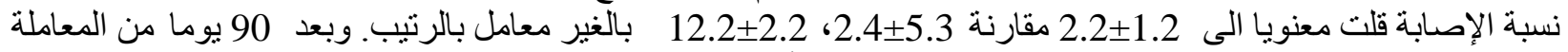

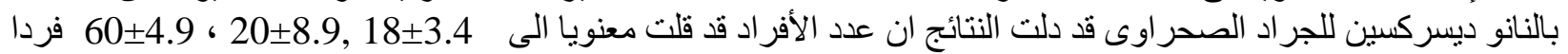

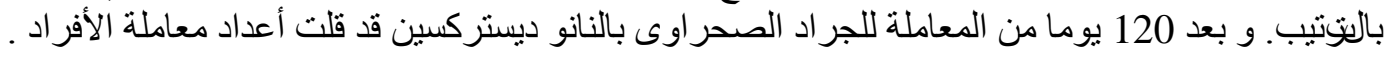

